\title{
Is it time for national systems of care for valvular heart disease?
}

\author{
(4) \\ Michael Mack*, MD; Mohanad Hamandi, MD \\ Baylor Scott \& White Health, Dallas, TX, USA
}

Looking back to two decades ago, the decision-making process for the management of patients with valvular heart disease was a relatively straightforward one compared to today. Patient management decisions could be largely distilled down to first, does the patient with valvular heart disease have symptoms sufficiently severe that surgical valve replacement is indicated? And second, if valve surgery is performed, what type of valve should be placed, tissue or mechanical? Now of course, this is a gross oversimplification of the care of patients with valvular heart disease 20 years ago that does a disservice to those practitioners then caring for patients. However, it does serve as a comparison to contrast with the complexity of current Heart Team approaches that are now required to care for valvular heart disease patients optimally. Advances have occurred in all aspects of care and have created a tsunami effect, making the challenges in the complexity of care at times quite daunting.

There are a number of factors that have contributed to these current challenges of delivering best care, from the sheer increase in the number of patients now able to be identified with valve disease, to the diagnostic imaging modalities available to assess the presence and severity of valvular disease, to the availability of a broad array of therapeutic options heretofore non-existent. Examples of some diagnostic dilemmas include is the patient symptomatic? Are the symptoms due to the valve disease? Should the patient undergo stress testing? Is frailty present and, if so, is it sufficiently severe to preclude treatment? What imaging modalities are available to assess the severity of disease and aid clinical decision making? Does the practitioner have ready access to 3D echocardiography, 4D multislice high-resolution computerised tomography and cardiac magnetic resonance imaging? If so, is there sufficient access to advanced imaging specialists who are expertly skilled in interpretation of these studies?

In the USA, there are approximately 1,150 heart surgery programmes and 1,600 cardiac catheterisation laboratories. How many of these programmes have (or could reasonably be expected to build) sufficient infrastructure and personnel to care for patients with valvular heart disease expertly? There are currently 570 programmes in the USA that perform transcatheter aortic valve implantation 
(TAVI) and 280 programmes that perform transcatheter mitral therapy ${ }^{1}$. Is that the right number of programmes to have and maintain sufficient levels of expertise in the care of patients with valvular heart disease while providing sufficient access to care for most or all patients who need it? Alternatively, should all centres which have cardiac surgery and interventional cardiology programmes be expected to provide some aspect of valvular heart disease care? Can they do so and maintain excellence in all aspects of care and can their institutions afford to provide sufficient capital expenditures to do so? Striking the right balance of maintaining excellence in care while providing patients with sufficient access to care is the key to a successful system of care.

To try to define and implement such a balance, there are new proposals posited in both Europe and the USA to create "systems of care" for diagnosing, managing and treating valve disease patients. The operating principle of both is to provide the right treatment, to the right patient, at the right time, while taking into account the patient's wishes. Although this system of care concept is a relatively recent one for the management of patients with valvular heart disease, it is not a new concept in healthcare for the treatment of other diseases. Numerous examples exist in the USA that serve as precedent for a valve disease system of care. Starting in 1960, the National Cancer Institute in the USA created a highly successful nationwide three-tiered system for cancer care ${ }^{2}$. The American College of Surgeons in 1976 built a universally adopted four-tiered system of trauma centres ${ }^{3}$. Likewise, national systems of care have been built for acute stroke management (Brain Attach Coalition), treatment of acute myocardial infarction (ACC/AHA door-to-balloon time programme) and bariatric surgery centres for patients with obesity ${ }^{4-6}$. Building on the experience and lessons learned from the national programmes for management of these conditions, national systems of care for patients with valvular heart disease are being proposed in both Europe and the USA.

A pilot programme for TAVI exists that gives some insight into how a system of care could work. In the Canadian province of British Columbia, a province-wide programmatic approach has been undertaken ${ }^{7,8}$. There are four programmes performing TAVI in the province. They are linked together in a network in which three "primary valve centres" perform transfemoral TAVI while more complex patients with extensive comorbidities and/or needing alternative access approaches or valve-in-valve procedures are referred to a single advanced tertiary valve centre in Vancouver. Open lines of communication, readily available consultation and mentoring are maintained within the network. With TAVI, in which there is evidence for a "volume-outcome" relationship, they seem to have struck the right balance between maintaining optimal care while providing broad geographic patient access 9 .

So, can this concept of a valve network system of care be scaled to a national level? Would this concept work equally well in Europe and the USA with markedly different models of healthcare delivery? One of the reasons for the successful implementation of a programme in a Canadian province is the existence of a single payer national healthcare system and a province-wide healthcare authority willing to approve it. Implementation of such a system in the USA, which has a more heterogeneous healthcare system with multiple payers, is significantly more problematic. This is further compounded in Europe with many different models of healthcare delivery in various nations from a largely nationalised system in the United Kingdom to a large private insurance sector in Germany with many degrees of variability in between.

One proposal as to what a valvular heart disease system of care might look like has recently been published by the European Society of Cardiology (ESC): "Standards defining a 'Heart Valve Centre': ESC Working Group on Valvular Heart Disease and European Association for Cardiothoracic Surgery Viewpoint"10. The proposed standards require, at a minimum, that a valve centre have a valve specialist clinic and a multidisciplinary Heart Team. The group further establishes standards for imaging, range of procedure availability, processes of care, collaborative services, training and data review.

A similar proposal by four professional societies in the USA, the American College of Cardiology, American Association for Thoracic Surgery, Society for Cardiovascular Angiography and Interventions and the Society of Thoracic Surgeons, has been posited for peer review and public comment. The feedback that has been received is currently being considered as the proposal is finalised. The vision proposed is to establish two tiers of valve centres. All centres would be expected to have advanced imaging capabilities, a Heart Team approach to patient care that participates in shared decision making and to meet or exceed quality outcome benchmarks. Participation in national registries, public reporting of outcomes and research trials would also be expected. One tier, primary valve centres, would be capable of performing isolated surgical aortic valve replacement and mitral valve repair of the posterior leaflet. as well as transfemoral TAVI and balloon aortic valvuloplasty. The second tier, advanced valve centres would be expected to perform all levels of complexity of surgical and catheter-based care for valves and related diseases.

Clearly, successful implementation of such a system in Europe and the USA will meet with significant obstacles and challenges. However, as mentioned above, a precedent exists in systems of care for other diseases that has resulted in improved patient outcomes. The overarching, guiding principle of a system of care for valve disease patients is to optimise the care of the individual patient by providing adequate access to the right care, at the right place, and the right time, while respecting his/her own preferences and values. It can and should be done! It is time!

\section{Conflict of interest statement}

M. Mack is co-Principal Investigator, without compensation, for research trials for Abbott Vascular, Edwards Lifesciences and Medtronic. M. Hamandi has no conflicts of interest to declare.

\section{References}

1. Grover FL, Vemulapalli S, Carroll JD, Edwards FH, Mack MJ, Thourani VH, Brindis RG, Shahian DM, Ruiz CE, Jacobs JP, 
Hanzel G, Bavaria JE, Tuzcu EM, Peterson ED, Fitzgerald S, Kourtis M, Michaels J, Christensen B, Seward WF, Hewitt K, Holmes DR Jr; STS/ACC TVT Registry. 2016 Annual Report of The Society of Thoracic Surgeons/American College of Cardiology Transcatheter Valve Therapy Registry. J Am Coll Cardiol. 2017; 69:1215-30.

2. Birkmeyer NJ, Goodney PP, Stukel TA, Hillner BE, Birkmeyer JD. Do cancer centers designated by the National Cancer Institute have better surgical outcomes? Cancer. 2005; 103:435-41.

3. MacKenzie EJ, Rivara FP, Jurkovich GJ, Nathens AB, Frey KP, Egleston BL, Salkever DS, Scharfstein DO. A national evaluation of the effect of trauma-center care on mortality. $N$ Engl J Med. 2006;354:366-78.

4. Alberts MJ, Latchaw RE, Selman WR, Shephard T, Hadley MN, Brass LM, Koroshetz W, Marler JR, Booss J, Zorowitz RD, Croft JB, Magnis E, Mulligan D, Jagoda A, O'Connor R, Cawley CM, Connors JJ, Rose-DeRenzy JA, Emr M, Warren M, Walker MD; Brain Attack Coalition. Recommendations for comprehensive stroke centers: a consensus statement from the Brain Attack Coalition. Stroke. 2005;36:1597-616.

5. Jollis JG, Al-Khalidi HR, Roettig ML, Berger PB, Corbett CC, Dauerman HL, Fordyce CB, Fox K, Garvey JL, Gregory T, Henry TD, Rokos IC, Sherwood MW, Suter RE, Wilson BH, Granger CB; Mission: Lifeline STEMI Systems Accelerator
Project. Regional Systems of Care Demonstration Project: American Heart Association Mission: Lifeline STEMI Systems Accelerator. Circulation. 2016;134:365-74.

6. Azagury D, Morton JM. Bariatric Surgery Outcomes in US Accredited vs Non-Accredited Centers: A Systematic Review. J Am Coll Surg. 2016;223:469-77.

7. Stub D, Lauck S, Lee M, Gao M, Humphries K, Chan A, Cheung A, Cook R, Della Siega A, Leipsic J, Charania J, Dvir D, Latham T, Polderman J, Robinson S, Wong D, Thompson CR, Wood D, Ye J, Webb J. Regional Systems of Care to Optimize Outcomes in Patients Undergoing Transcatheter Aortic Valve Replacement. JACC Cardiovasc Interv. 2015;8:1944-51.

8. Mack M. Balancing Optimal Outcomes With Access to Care. It Can Be Done! JACC Cardiovasc Interv. 2015;8:1952-3.

9. Carroll JD, Vemulapalli S, Dai D, Matsouaka R, Blackstone E, Edwards F, Masoudi FA, Mack M, Peterson ED, Holmes D, Rumsfeld JS, Tuzcu EM, Grover F. Procedural Experience for Transcatheter Aortic Valve Replacement and Relation to Outcomes: The STS/ACC TVT Registry. J Am Coll Cardiol. 2017;70:29-41. 10. Baumgartner H, Falk V, Bax JJ, De Bonis M, Hamm C, Holm PJ, Iung B, Lancellotti P, Lansac E, Rodriguez Muñoz D, Rosenhek R, Sjögren J, Tornos Mas P, Vahanian A, Walther T, Wendler O, Windecker S, Zamorano JL; ESC Scientific Document Group. 2017 ESC/EACTS Guidelines for the management of valvular heart disease. Eur Heart J. 2017;38:2739-91. 